\title{
Does the Behavioral Science Curriculum in a Private College Fit the Needs of the Job Market?
}

\author{
Rachel Pasternak \\ ${ }^{1}$ School of Behavioral Sciences, The College of Management Academic \\ Studies Division (COMAS), Rishon Lezion, Israel \\ Email:paster@colman.ac.il
}

Received October $5^{\text {th }}, 2013$; revised November $5^{\text {th }}, 2013$; accepted November $12^{\text {th }}, 2013$

\begin{abstract}
Copyright (C) 2014 Rachel Pasternak. This is an open access article distributed under the Creative Commons Attribution License, which permits unrestricted use, distribution, and reproduction in any medium, provided the original work is properly cited. In accordance of the Creative Commons Attribution License all Copyrights (C) 2014 are reserved for SCIRP and the owner of the intellectual property Rachel Pasternak. All Copyright (C) 2014 are guarded by law and by SCIRP as a guardian.
\end{abstract}

\begin{abstract}
The perception of knowledge as consumer goods appeared with the development of private education and reflects a marketing or consumer needs approach. The consumer-needs approach sees advantages in adapting higher education to the needs of the consumer. This article examines whether the behavioral science curriculum (scope, and content) in the private college is based on the approach of knowledge as consumer goods. In addition, what is the level of satisfaction expressed by the alumni of the course, i.e. those who completed the curriculum? The study used a multi-method approach, combining textual analysis of archived documents and an online questionnaire survey of 250 alumni. The results: the scope and contents of the curriculum were only partially affected by this approach. Nonetheless, the graduates were very satisfied with the curriculum's contribution to their personal and professional skills and occupations.
\end{abstract}

Keywords: Evaluation; Satisfaction; Curriculum; Knowledge as Consumer Goods; Private College; Behavioral Sciences

\section{Case Study}

For many years, the only way to obtain a higher education in Israel was to attend one of a handful of public universities; these institutions of higher learning had developed good reputations and were internationally recognized. Degree-granting colleges associated with these universities only began to develop in Israel in the 1980s. These colleges expanded and multiplied in the 1990s in a manner similar to the corresponding phenomenon in Portugal, where more than one-third of the higher educational institutions were private (Levy, 2010), and Thailand, in which the private institutions constituted twenty percent (Praphamontripong, 2010). The rapid expansion of private higher education and the development of private degree-granting colleges have formed a dominant theme in the study of private higher education, in Israel and abroad. However, while private colleges have continued to develop in Israel, the last five years (2005-2010) have seen a decline of private higher education in other places around the world, leading to research efforts to identify the dynamics and causes of the decline. The literature cites two broad categories of causes for the decline: social factors (such as demographic shifts), or political policy (Levy, 2010; Slantcheva-Drust, 2010; Uribe, 2010).

Although the quality of higher education curricula in Israel is reviewed and approved by the Council for Higher Education (CHE) to ensure that the proposed curriculum fulfills the academic and professional needs of the discipline, doubts about quality persist. The possibility exists that curricula in private colleges, built on the perception of knowledge as consumer goods, can become popular and appealing to its consumersstudents but lack robust academic and ideological foundations. Considerations of the "the need of the client" can create curricula that meet the students' desires, but do not have the appropriate professional underpinnings.

The aim of this article is to evaluate the curriculum of a behavioral science bachelor's degree program at the largest private college in Israel, and examine whether the curricula is affected by the college's view of knowledge as goods. We will ask if the curricula's stated goals, structure, scope and contents assign center place to knowledge, or whether they assign greater importance to providing the professional qualifications that are needed by the consumer student.

\section{Evaluating the Curriculum}

During the last three decades, special attention has been paid to planning and preparing curricula at every level of teaching. The introduction of new teaching systems led to the need to create new curricula that are appropriate for recent developments. National and private centers were established in many countries to plan curricula. With the creation of these new curricula came the need to integrate evaluation into the development process. A critical review of the professional literature that addresses the evaluation of curricula indicates a number of characteristics:

The first stage of curriculum evaluation models appeared in the literature that was published during the 1970s and 1980s. A wide array of models was presented leading to confusion and 


\section{R. PASTERNAK}

differences of opinion regarding the best model. These evaluation models included, for example, "Reactive Evaluation" (Lewy, 1973), “Ontological Evaluation” (Peper, 1973), and a plethora of other models, such as those proposed by Eisner (1979), Ariav (1986) and others. It is interesting to note that agreement exists amongst curriculum evaluators concerning the lack of standardized evaluation models and regarding the legitimacy of utilizing eclectic models (Nevo, 1995). Some models evaluate results while others assess cost-benefit or input-output (Peres \& Pasternak, 1993). However, almost no evaluation studies have been conducted that examine the relationship between the curriculum and its stated goals and objectives.

The second stage is the most recent wave of evaluation studies, which also exhibit a wide range of approaches regarding evaluation; these approaches have almost nothing in common. An in-depth examination indicates that the majority of evaluation studies focuses on the results of the curriculum and its effectiveness. Examples abound: An evaluation was conducted on a curriculum for treating the elderly, which examined the curriculum's effectiveness and its results (Speziale, Black, Coatsworth-Puspoky, Ross, \& O’Regan, 2009). Another study examined the impact of a national mathematics curriculum on the way teachers functioned (Haser \& Star, 2009). The ramifications and results of an innovation, like learning outside of the school, are the focus of a recent evaluation (Nundy, Dillon, \& Dowd, 2009). Similarly, an evaluation was conducted on the outcome of a school curriculum in China (Xu, 2009). The effectiveness and outcomes of a mathematics curriculum were evaluated (Graves et al., 2009).

The third stage is based on the perception of knowledge as consumer goods and evaluate the curricula by asking if it fits the needs of the job market.

The following three studies are examples of this approach:

1) In China, a Business Management curriculum was evaluated by means of a survey conducted among businesses. The study findings indicate that the curriculum attempted to adapt the study material to the needs of the job market (Meleki, 2009).

2) At a technological college, attempts were made to incorporate the professional demands in the field based on the opinions of professionals and alumni who are employed in technology. The evaluation was conducted in order to examine the effectiveness and outcome of this approach (Tubaishat, Lanrari, \& Al-Rawi, 2009).

3) In China, an evaluation was made of a curriculum that was created on the basis of the professional requirements of employers (Velde, 2009).

This study adopts the third stage of evaluation and examine the curricula by its linkage to professional needs. We will do it in two ways, first examining the scope and the contents of the curricula and second exploring the satisfaction of the consumers-the graduates from the curricula.

\section{The Perception of Knowledge as Consumer Goods}

The perception of knowledge as consumer goods appeared with the development of private education and reflects a marketing or consumer needs approach. This approach dictates a unique mode of behavior with respect to the importation (transmission) of knowledge, beginning with its marketing and concluding with the determination of its curriculum. The type of knowledge, its substance and method of transmission are influenced by, and adjusted to, the consumer's needs. This approach is revolutionary when compared to the classical concept of higher education, which framed knowledge as an absolute entity and offered it to the consumer public without any reference to consumer needs or satisfaction. In contrast, the knowledge as a consumer good approach gives rise to a different conceptualization of the educational process (Pasternak, 2004; 2013).

The consumer-needs approach sees advantages in adapting higher education to the needs of the consumer. These adaptations are generally carried out in private educational institutions, and are especially important in the technological sphere (Overton, Volkman, Silver-Pacuilla, \& Gray, 2008; Tubaishat, Lanrari, \& Al-Rawi, 2009) or in business administration (Dubas, Ghani, Davis, \& Strong, 1998; Dailey et al., 2006). This approach is also trickling down to the public universities, some of which try to pinpoint the needs of the student-consumer. A study carried out in the United States examined the needs of students from seven countries, and found similarities between their expectations and needs (Shah \& Laino, 2006). Adherents of the approach claim that it is appropriate for all forms of study and can improve academic systems and processes (Barrows \& Murray, 1997). Even the Soviet educational system has started to adopt this approach in the last fifteen years (Grudzinskii, 2005).

However, researchers find fault with adapting higher education to the needs of the consumer and claim that the knowledgeas-consumer-goods approach mightassign lesser importance to theoretical knowledge per se, and instead base its academic curricula on the professional demands of employers and emphasize professional and personal skills instead (Velde, 2009; Tubaishat, Lansari, \& Al-Rawi, 2009; Meleki, 2009). These adaptations to the needs of the market place can impinge on other professional requirements, such as the need of professionals to acquire broad knowledge bases in their fields (Heckman \& Montera, 2001). Due to the fact that the needs of employer-consumers in the profession can affect the expectations of the students-consumers, this can impact the creation of the curricula. A curriculum based mainly on the needs of the consumer-employer is perhaps appropriate for professions such as the exact sciences, technology or business administration. However, it may be less suitable for the social and behavioral sciences because the wide scope of basic theoretical knowledge needed for these professions, is not always compatible with the needs of the consumer-employer. Even more problematic is that the sphere of knowledge in these domains is so broad with many interdisciplinary aspects, that there is no consensus regarding knowledge-acquisition needs. Thus, this article examines whether the behavioral science curriculum in the private college is based on the approach of knowledge as consumer goods.

The literature above leads us to the central hypothesis of this study: that the consumer-goods approach will affect the behavioral science curricula and will also be expressed by graduates regarding the contribution of the changed curricula to their professional qualifications. The practical implications of this theory are:

1) Acquisition of professional qualifications will assume a relatively greater percentage than theoretical knowledge. As a result, all the segments of the curriculum, the scope and content, will emphasize the acquisition of professional qualifications.

2) The curriculum will be evaluated according to its contri- 


\section{R. PASTERNAK}

bution to the acquisition of professional qualifications. Graduates of the behavioral sciences will express satisfaction regarding the contribution of the curriculum to their professional qualifications.

\section{Method}

\section{General}

Variables

In order to answer these questions we analyze the objectives, structure, scope and content of the curriculum and examine the relative ratio of theoretical knowledge to professional qualifications in the coursework.

1) Theoretical knowledge is defined as the sphere of knowledge intended to enrich the student's theoretical basis in the domains of sociology, psychology, anthropology and philosophy-the basic subjects in the behavioral sciences. Theoretical knowledge includes subjects involving theories, theoreticalresearch information, social policy and statistical information.

2) Professional qualification is defined as the sphere of knowledge aimed at professional training and inculcating skills that will contribute to the professional occupation. All of the courses in this sphere appear under the rubric of "professional cluster" and are structurally distinct in the curriculum.

3) Scope - the number of credits (or credit points) that students are required to take during their studies. This will be calculated out of the actual curriculum offered to the students.

4) Content-the content of the courses will be analyzed according to the syllabus for each course.

6) The curriculum encompasses numbers 3 , and 5 as listed above: the number of credits (scope), and the syllabi of the courses (content).

7) Satisfaction-will be measured by a questionnaire that asks graduates for their level of satisfaction regarding the contribution of the curriculum to their professional qualifications and occupations.

\section{Materials}

The study used a multi-method approach, combining textual analysis of documents with an online questionnaire survey of 250 alumni.

A textual analysis was performed on the contents listed in the documents. Other documents were official, public texts detailing the curriculum for students. We used also syllabuses (or syllabi) that describe the topics of the courses in detail in order to distinguish between courses focusing on theoretical knowledge and those focusing on professional qualifications. We are aware about the limitation of using syllabuses since class teaching is not necessarily the same as the syllabuses.

The survey presents data from a questionnaire distributed to the college's alumni in which they express their opinion on the connection between the curriculum and their professional skills. The questionnaire posed the following questions: Did the curriculum help them both personally and professionally? Regarding their professional experience, which courses contributed the most and which courses would they suggest adding or strengthening? This information gives us perspective in evaluation of the curriculum.

\section{Participants}

The survey was conducted among alumni of the School of
Behavioral Sciences (SBS) who graduated within the last 10 years.

Two hundred and fifty graduates who received their degrees from the college in 1997-2007 answered an internet questionnaire (out of 900 graduates registered on the alumni forum) according to the following distribution: $13.11 \%$ male, $86.89 \%$ female; age group: 26 - 30-60.66\%; 31 - 35-30.33\%; 36 - 40 $-7.38 \%$; and $41+-1.64 \%$. Marital status: $43.03 \%$ single, $56.97 \%$ married. Fifty percent continued their studies, generally for a master's degree, and 91\% were employed 2 - 9 years in a wide variety of fields and positions in the domain of behavioral sciences: Organization consulting-5.33\%; managementtraining, coordinators, executive, office, secretarial, department manager 56.95\%; miscellaneous (with people)-20.50\%; education-6.56\%; marketing and banking-9.02\%; therapy $1.64 \%$.

\section{Procedure}

Data was collected over the course of a year (2010), by the researcher and paid assistants. During the last yearsthere were changes of courses but they were not examined in this study. In order to provide in-depth evaluation, we conducted a survey among all Behavioral Science alumni who graduated within the last 10 years. We asked the graduates for their feedback on the curriculum. Did the courses benefit them both personally and professionally? Which courses contributed the most to their professional experience and which courses would they suggest adding or strengthening? This information gives us another perspective in evaluating the effect of the knowledge-as-consumer-goods outlook, on the curriculum.

The questionnaire that was filled out by the graduates was not intended originally for this research study, but was given to them by the Behavioral Sciences School for feedback regarding adapting the curriculum to professional qualifications. The very fact that such a questionnaire was disseminated, testifies to the great importance given by the school to tailoring the curriculum to the needs of the student-consumer. Two hundred and fifty graduates filled out the graduates' survey, out of approximately 900 graduates that are registered on the alumni forum.

\section{Results}

Hypothesis 1: Acquisition of professional qualifications will assume a relatively greater percentage than theoretical knowledge. As a result, all the segments of the curriculum, the scope and content, will emphasize the acquisition of professional qualifications.

\section{Scope}

The scope of study ranges from 114 to 128 credits. The course distribution (based on an average of 122 credits) is as follows: Introductory courses: 10 credits or $8.5 \%$; Required courses: 60 credits or 49\%; Electives: 10 credits or $8.5 \%$; Professional Clusters: 30 credits or 24\%; Seminars: 6 credits or 5.5\%; Experiential Learning Program (not mandatory): 6 credits or $5.5 \%$.

Analysis of the scope: The inclusion of "Professional Clusters" clearly testifies to the influence of the knowledge-asconsumer-goods approach, because the curriculum could have included only subjects directly connected to the behavioral sciences as the universities do. (Only one Israeli university offers behavioral sciences, and it does not offer any form of profes- 


\section{R. PASTERNAK}

sional cluster courses.)

The inclusion of the professional cluster clearly results from the desire to adapt the curriculum to the needs of the studentclient. Nevertheless, an analysis of the distribution of all the courses yields a different picture entirely.

The course distribution between courses imparting theoretical knowledge and those that impart professional qualifications in the scope (122 credits) is as follows:

1. Theoretical Knowledge: Introductory courses: all the credits, 8.5 percent; Required courses: 75 percent of 60 credits is 45 credits, or 37 percent; Electives: all the credits, 8.5 percent; Professional cluster: 21 percent of 30 credits is 6 credits or 5.5 percent; Seminars: all the credits, 5.5 percent: Experiential learning: 5.5 percent. Total: $70 \%$.

2. Professional Qualifications: Required credits: 25 percent of 60 credits are 15 credits or 12 percent; Professional cluster: 79 percent of 30-to- 24 credits are approximately 20 percent. Total: 30\% (approximately).

These results show that despite the addition of a professional cluster, the large majority of the coursework (70\%!) is devoted to theoretical knowledge while only $30 \%$ is devoted to professional qualifications.

\section{Content}

In order to determine the proportion of the subject matter that is dedicated to applied professional qualifications, a content analysis was performed on 106 syllabuses which describe the course content in depth.

Introductory courses: 5 courses (10 credits) are taken in the first year only, in both semesters. They include the theoretical basis of the behavioral sciences; the basics of humanistic and social thinking. All 5 courses focus on theoretical knowledge.

Required: 18 courses (60 credits): These include basic courses in psychology, sociology, philosophy and anthropology that are taken over a three-year period. These courses provide students with single-discipline and interdisciplinary knowledge, both empirical and theoretical, and constitute an academic foundation for the elective courses and seminars. In the first year, the required courses include several single-discipline and interdisciplinary subjects such as the biological elements of human behavior, learning, development and socialization. During the second year the required courses teach the psychological and social elements in the formulation of social policy. During the third year the courses deal with Israeli society, psychopathology and deviance in Israeli society. The following required courses teach research skills and are offered in the first and second years: Research Methods, Statistics, Computer Usage and Library Instruction, Tests and Measurement.

Out of the 18 courses offered above, 14 focus on theoretical knowledge (7-disciplinary knowledge and 7-interdisciplinary knowledge; 4 courses offer professional skills.

Electives: 24 courses: (10 credits): The interdisciplinary nature of the program is reflected in the elective courses and the variety of subjects connected with the social sciences and humanities. Twenty-four elective courses are offered which deal with psychological, sociological, anthropological, philosophical and educational aspects, such as Love; Dealing with Domestic Problems and Crises; Ethics and the Good Life; Journey to Urbanization: Bachelorhood, Marriage and Everything in Between; Backpacking as a Maturation Process; Religion, Psychology and Existentialism; State, Communications and De- mocracy in the Arab World; Literature, Deviance and Writing; and Madness and Normalcy in the New Age.

Some of the elective courses are taught simultaneously by two different lecturers who specialize in different disciplines. The two lecturers conduct a dialogue in the classroom and lecture in turn. An examination of the content of the elective courses shows a similar scope of sociological and psychological content and a minimum of philosophical and anthropological content. The elective courses are offered to third-year students, though second-year students are permitted to register on the basis of availability. All 24 courses emphasize theoretical knowledge (2-disciplinary and 22-interdisciplinary knowledge).

Seminars: 15 courses (6 credits): Fourteen to 15 seminars are offered that deal with a broad spectrum of interdisciplinary subjects. For example: Sex, Gender, Love: a Contemporary View of Soap Operas; Education, Society and Ideology; Sensation Seeking and Risk Taking on the Roads; Humor is No Joke; and Sounds and Silence. All students are required to attend one seminar. All 15 seminars focus on theoretical disciplinary knowledge.

Professional Cluster section: The students select one professional cluster out of the following three options:

Management, Organizational Behavior, and Human Resources Cluster. The program includes 26 - 30 credits of required courses and 4 credits of elective courses, for a total of 30 - 34 credits.

Communications Cluster: The program includes requiredcourses, elective courses and workshops, for a total of 28 - 30 credits.

Criminology and Law Enforcement: The program includes required courses, elective courses and a seminar, for a total of 34 credits.

Out of the 38 courses offered in the professional cluster, about 8 focus on theoretical knowledge.

The Experiential Learning Program (6 courses) is open to select Behavioral Sciences students who are interested in combining their theoretical studies in the department with practical volunteer field work. The program gives added value to the students, above and beyond their theoretical studies in the department. An integral part of the program is the development of personal and professional skills which are required in today's world in order to integrate successfully into graduate studies and achieve a professional career, and also to enrich the students' personal and social lives.

Analysis of the content: How is the content distributed between theoretical knowledge and applied professional training?

a) Theoretical knowledge: There is a wide spectrum of single-discipline and interdisciplinary theoretical knowledge-based courses: 5 introductory courses, 14 required courses, 24 electives, 15 seminars and 8 from the professional cluster. Total: 66 courses or 66 percent of the structure.

b) Professional Qualifications: 4 required (professional skills) and 30 (from professional cluster). Total: 34 courses or 34 percent of the total.

Regarding "imparting of values" that appears in the Goals Statement: None of the course syllabuses (in the structure) makes mention of instilling values. Only the Experiential Learning Program emphasizes volunteerism as a value and the program is not even compulsory for all students.

The knowledge-as-consumer-goods approach, were only partially reflected in the Scope, and Content sections: Scope-only 


\section{R. PASTERNAK}

$30 \%$ of the credits are dedicated to professional qualifications (and $70 \%$ of theoretical knowledge); and Content-only 34\% of the courses are dedicated to professional qualifications (and $66 \%$ of theoretical knowledge).

The analysis of the courses provides interesting findings. Although theoretical knowledge constitutes $70 \%$ of the credits (scope) and $66 \%$ of the courses. Professional knowledge and professional skills account only $25 \%$ of the scope and $34 \%$ of the course content.

This information indicates that while the private college adopts an approach that reflects the perception of knowledge as consumer goods this is not reflected in the actual courses and required credits with their traditional emphasis on theoretical knowledge. Perhaps, then, the proclaimed goals of the college reflect a desire to attract students by promising skills that will enable them to succeed in the professional marketplace, even though the curriculum does not carry through on these goals.

Summary: We analyzed the curriculum's scope, and content to determine whether they correspond to the stated goals. We discovered that there is only a partial correspondence and that to a large extent, the overall viewpoint of knowledge as consumer goods is not reflected in the college curriculum. Thus we deduce that Hypothesis 1 was only partially supported.

Hypothesis 2 was that the program graduates would express great satisfaction with the curriculum regarding its contribution to their professional skills and occupations.

\section{Satisfaction with the Curriculum}

We tried to examine the extent to which the goals and objectives were achieved among those graduates who are already working, and to evaluate the contribution of their studies to their respective professions. We asked: Which courses contributed to your professional skills? All the courses that were noted (there was no restriction on the number of courses) - 521 (were divided into two categories. First category: micro courses that focus on the individual in groups and organizations; and second category: macro courses that focus on society as a whole. The following courses were also included: professional clusters, professional skills and the Experiential Learning Program.

The results, as shown in Table 1 , indicate that the management courses contribute the most to professional skills, about $38 \%$. It should be noted that most of the students in the Behavioral Sciences School choose the management cluster, and that fewer students choose the other clusters. Second place, about $31 \%$, was assigned by the graduates to courses focusing on the individual.

The second category classified the courses according to the Goal model: theoretical knowledge, which includes both single-discipline and interdisciplinary knowledge, cluster and professional skills. Here, too, the cluster courses contributed more to professional skills, about 51\% (as shown in Table 2). Although this figure is reasonable, theoretical knowledge courses (single-discipline and interdisciplinary courses) contributed about $42 \%$, which is also high. Evidently, the graduates attributed their professional skills to the combination of professional qualification courses and theoretical knowledge courses.

We also asked whether their studies had contributed to the graduates' social and personal skills. Here we received 323 courses compared to 521 courses that contributed to profess-
Table 1.

Courses that have contributed to professional skills.

\begin{tabular}{ccc}
\hline Category & Frequency & $\begin{array}{c}\text { Relative Frequency } \\
\text { in Percent }\end{array}$ \\
\hline Individual & 161 & 30.90 \\
Groups and Organizations & 6 & 1.15 \\
Society & 53 & 10.17 \\
Communications & 12 & 2.30 \\
Criminology & 18 & 3.45 \\
Management & 18 & 3.45 \\
Learning Skills & 196 & 37.62 \\
Tid Not Contribute/Not Relevant & 25 & 6.14 \\
Total & 521 & $4.80 \%$ \\
\hline
\end{tabular}

Table 2.

Courses that have contributed to professional skills.

\begin{tabular}{ccc}
\hline Course & Frequency & Relative Frequency in Percent \\
\hline Clusters & 100 & 50.76 \\
Learning/Professional Skills & 14 & 7.11 \\
Interdisciplinary Knowledge & 21 & 10.66 \\
Single-Discipline Knowledge & 62 & 31.47 \\
Total & 197 & 100.00
\end{tabular}

sional skills. Out of these, the courses that focus on the individual are the greatest contributors to social and personal skills, about $47 \%$, followed by courses that focus on organizations and society, about $19 \%$ (as shown in Table 3). The Experiential learning Program, even though it entails a limited number of course hours and is optional for the students, accumulated a fairly high rating for contribution to social and personal skills, about $14 \%$.

Another question examined the contribution of the curriculum to general knowledge and to analytical ability and evaluation skills. The results indicate that the curriculum contributed greatly to the graduates' theoretical knowledge. Of the respondents, $76 \%$ reported a great or a very great contribution to knowledge and $57 \%$ reported a great or a very great contribution to analytical ability. A majority of $59 \%$ reported that the curriculum's courses contributed greatly to their abilities to express themselves orally and in writing. A similar number, $60 \%$, reported the curriculum's great contribution to interpersonal relations-personal skills. Overall, $70 \%$ of the graduates expressed high or very high levels of satisfaction with the courses.

Thus the results of the survey lead to a very interesting conclusion, in which the graduates expressed a high level of satisfaction with the curriculum and its goals (even though the curriculum places less emphasis on professional qualifications than does the Goal Statement). Apparently, the graduates related to the curriculum as a whole and expressed satisfaction with the 


\section{R. PASTERNAK}

Table 3.

Courses that contributed to social/personal skills.

\begin{tabular}{ccc}
\hline Category & Frequency & $\begin{array}{c}\text { Relative Frequency } \\
\text { in Percent }\end{array}$ \\
\hline Individual & 152 & 47.06 \\
Groups and organizations & 11 & 3.41 \\
Society & 50 & 15.48 \\
Experiential learning & 45 & 13.93 \\
Communications & 12 & 3.72 \\
Criminology & 4 & 1.24 \\
Management & 34 & 10.53 \\
Learning skills & 2 & 0.62 \\
Did not contribute/not relevant & 13 & 4.02 \\
\hline
\end{tabular}

coursework devoted to knowledge as well as the courses that contribute to developing their professional skills. A closer, more precise examination, however, shows that a preference exists for those disciplines that contribute to professional and personal skills.

The professional clusters contribute to professional qualifications while the single-discipline theoretical knowledge courses reinforce those skills and contribute significantly to social and personal skills. The Experiential Learning Program brings together all these contributions to the professional and personal skills.

These findings support Hypothesis 2: that graduates will evaluate the success or failure of the curriculum according to its contribution to their acquisition of professional qualifications and skills. The explanation lies at the very essence of the behavioral sciences: that theoretical knowledge in this interdisciplinary field contributes indirectly to professions involving contact with human beings. Professional qualifications contribute directly to these professions, but knowledge in all its varied facets (theoretical and applied), raises the professional level of those who work with people.

\section{Discussion}

The expansion of higher education in industrial nations and its greater accessibility to the layperson raises the question: Is higher education directed toward the needs of the student-consumer, and are curricula constructed according to the professional demands of the employment market? Higher education that attempts to fulfill the needs of the student-consumer, evolves from the perception of knowledge as consumer goods.

This situation is what differentiates the private college from the university; the latter places a greater emphasis on theoretical knowledge while the private college tries to fulfill the students' desires and offer them the applied knowledge they will need for their careers. This study evaluates the curriculum that leads to a B.A. degree in behavioral science at a large, established and prestigious private college in Israel.

The college's behavioral science curriculum is extremely popular; 280 - 300 students register for it each year, while only about one-third that number register for the analogous program in an Israeli university every year.
Does the curricula reflect the perception of knowledge as consumer goods? In other words, is the centrality of acquiring theoretical knowledge relinquished in favor of acquiring professional and personal skills? Do these goals reflect ideology or a professional perception?

The findings which are based on content analysis of documents and a survey of 250 graduates regarding the curriculum, show interesting results.

An analysis of the scope and the contents of the curriculum (that is, the contents of the actual courses) indicate that they are not affected by the perception of knowledge as goods. Thus, $62 \%$ of the scope and contents are devoted to theoretical knowledge, $38 \%$ to skills, and nothing to values-in stark contradistinction to the Goals Statement.

This finding is very interesting and perhaps explains what happens when private colleges adopt the knowledge-as-consumer-goods approach as part of their marketing strategy (Heckman \& Montera, 2001) and attempt to direct their Statement to the needs of the consumer (Dailey et al., 2006; Overton et al., 2008). The stated goals and declarations maybe constitute a type of "packaging" for the product, the bachelor's degree in behavioral science. Those who are interested in this degree, check the "packaging" to help them choose the college that suits their purposes. These potential students are not really interested in the acquisition of theoretical knowledge; instead, they want to acquire the training and professional skills that will enable them to integrate into the workforce. Thus, applicants are often encouraged to choose a private college because it offers Professional Cluster courses, but they do not necessarily examine the curriculum to see what proportion the skill-based courses constitute (Fuqian, 2006).

Thus, the study's findings regarding the influence of the knowledge-as-consumer-goods approach on the scope, and content of the curriculum, pointed to a possible inconsistency. Despite the emphasis placed on applied information and professional qualifications in the Goals Statement, theoretical knowledge still received the lion's share of coursework in contrast to professional qualifications. How do we explain this paradox?

In contrast to technological professions (such as engineering, business administration, etc.) whose study-programs train students for the relevant professional occupations, the behavioral sciences are a very broad, interdisciplinary field comprised of a variety of theoretical and applied subjects with no one welldefined professional occupation. Therefore, it is questionable whether a behavioral science curriculum would, indeed, be affected by the knowledge-as-consumer-goods approach. But our research supported our hypothesis that the knowledge-asconsumer-goods approach does affect the behavioral science curriculum, mainly in the following three aspects:

First of all, the Behavioral Sciences Department offers professional cluster electives, in addition to the general behavioral science classes. This structure gives professional guidance and orientation to the students, and does not exist in traditional university studies. These clusters are in addition to the "traditional" theoretical studies typical of behavioral science departments. The School also offers an Experiential Learning Program, offering students hands-on volunteer work (though it is not mandatory). Thus, the clusters (and Experiential Program when applicable) are very important in preparing the students for future careers and giving them the professional qualifications they need, despite the fact that these courses comprise 


\section{R. PASTERNAK}

only a small proportion of the overall curriculum.

Second, the Behavioral Sciences School takes an active role in obtaining feedback from its graduates about their level of satisfaction with the curriculum, regarding the curriculum's contribution to their professional qualifications and occupations. The results of the questionnaire show that the graduates were highly satisfied with the curriculum according to this measure.

\section{Conclusion}

It is important to address the issue of theoretical knowledge within the sphere of the behavioral sciences field. The behavioral sciences are interdisciplinary and include the domains of sociology, psychology, anthropology and philosophy. It aims to enrich knowledge about the human being and about human interaction with society. Thus, theoretical knowledge is, in effect, professional training for this field. Even those subjects that focus on theoretical knowledge, help prepare the students for their future careers in professions of the cluster groups: management, criminology and communication. Thus, even socalled theoretical subjects are no less important in preparing the student for a career in any field that involves human interaction. Private colleges realize this fact and thus continue to provide the requisite theoretical knowledge basis, while they simultaneously adopt the knowledge-as-consumer-goods approach in their Goals Statement to attract students and make their programs as attractive as possible. But although it is true that private colleges want to attract large numbers of students, they are also careful about creating and maintaining good reputations over the years; they know that successful graduates are their best advertisements. So when they create their curricula, they are careful to include the traditional academic subjects and theoretical knowledge-based courses, as the universities do. Then, they may add professional clusters and the like (for professions such as Organizational Behavior and Human-Resources Management, Criminology, and Communications). In short, though colleges tend to emphasize the knowledge-asconsumer-goods approach in their Goal Statements offered to applicants, they are often able to accomplish the dual objectives of providing both theoretical and applied knowledge-based courses, for the best of both worlds.

Thus we deduce that the behavioral science curriculum is partially affected by the knowledge-as-consumer-goods approach.

\section{REFERENCES}

Ariav, T. (1986). Curriculum analysis and curriculum evaluation: A contrast. Studies in Educational Evaluation, 12, 139-147. http://dx.doi.org/10.1016/0191-491X(86)90003-9

Barrows, R., \& Murray, B. (1997). Using quality function deployment to improve academic advising process. NACADA Journal, 17, 22-31. http://dx.doi.org/10.12930/0271-9517-17.1.22

Dailey, L., Anderson, M., Ingenito, C., Duffy, D., Krimm, P., \& Thomson, S. (2006). Understanding MBA consumer needs and the development of marketing strategy. Journal of Marketing for Higher Education, 16, 143-158. http://dx.doi.org/10.1300/J050v16n01_07

Dubas, K. M., Ghani, W. I., Davis, S., \& Strong, J. T. (1998). Evaluating market orientation of an executive MBA program. Journal of Marketing for Higher Education, 8, 49-59.

http://dx.doi.org/10.1300/J050v08n04_04

Eisner, E. W. (1981). On the differences between scientific and artistic approaches to qualitative research. Educational Researcher, 10, 5-9. http://dx.doi.org/10.3102/0013189X010004005
Fuqian, F. (2006). Are public enterprises inefficient?: Viewpoints of western scholars. Chinese Education and Society, 39, 83-90. http://dx.doi.org/10.2753/CED1061-1932390507

Graves, G. H., Sulewski, C. A., Dye, H. A., Deveans, T. M., Agras, N. M., \& Pearson, J. M. (2009). How are you doing? Assessing effectiveness in teaching mathematics. PRIMUS: Problems, Resources, and Issues in Mathematics Undergraduate Studies, 19, 174-193. http://dx.doi.org/10.1080/10511970802409222

Grudzinskii, A. O. (2005). The university as an entrepreneurial organization. Russian Education \& Society, 47, 7-25.

Haser, C., \& Star, J.-R. (2009). Change in beliefs after first year of teaching: The case of Turkish national curriculum context. International Journal of Educational Development, 29, 293-302. http://dx.doi.org/10.1016/j.ijedudev.2008.08.007

Heckman, P. E., \& Montera, V. L. (2001). School Administrator, 58, 40-46.

Levy, D. (2010). An international exploration of decline in private higher education. International Higher Education, 61, 10-12.

Lewi, A. (1973). The practice of curriculum evaluation. Curriculum Theory Network, 11.

Maleki, R. A. (2009). Business and industry project-based capstone courses: Selecting projects and assessing learning outcomes. Industry and Higher Education, 23, 91-102.

http://dx.doi.org/10.5367/000000009788146647

Nevo, D. (1995). School based evaluation: A dialogue for school improvement. Oxford: Pergamon.

Nundy, S., Dillon, J., \& Dowd, P. (2009). Improving and encouraging teacher confidence in out-of-classroom learning: The impact of the Hampshire Trailblazer Project in 3-13 curriculum practitioners. Education 3-13, 37, 61-73.

Overton, C., Volkman, C., Silver-Pacuilla, H., \& Gray, T. (2008). Understanding consumer needs through market research. Assistive Technology Outcomes and Benefits, 5, 4-18.

Pasternak, R. (2013). Evaluation of the behavioral science curriculum in a college, in the view of the perception of "knowledge as consumer goods": Case study. Education, 3, 72-78.

Pasternak, R. (2004). Knowledge as goods in the educational marketplace: The case of the Liverpool University Extension in Israel. Mediterranean Journal of Educational Studies, 9.

Peper, J. B. (1973). An ontological evaluation model. The AERA Conference, New Orleans, 25 February-1 March 1973.

Peres, Y., \& Pasternak, R. (1993). Community school in Israel. Tel Aviv: Eitav.

Praphamontripong, P. (2010). Downturn in Thailand. International Higher Education, 61, 14-15.

Shah, A., \& Laono, H. (2006). Marketing a U.S. university to international students: Which approach is best-Standardization, adaptation or contingency? An investigation of consumer needs in seven countries. Journal of Marketing for Higher Education, 16, 1-24. http://dx.doi.org/10.1300/J050v16n01 01

Slantcheva-Durst, S. (2010). Ups and downs across Central and Eastern Europe. International Higher Education, 61, 13-14.

Speziale, J., Black, E., Coatsworth-Puspoky, R., Ross, T., \& O’Regan, T. (2009). Moving forward: Evaluating a curriculum for managing behaviors in a geriatric psychiatry inpatient population. Gerontologist, 49, 570-576. http://dx.doi.org/10.1093/geront/gnp069

Tubaishat, A., Lansari, A., \& Al-Rawi, A. (2009). E-Portfolio assessment system for an outcome-based information technology curriculum. Journal of Information Technology Education, 8, 43-54.

Uribe, L. (2010). Decline in Colombia. International Higher Education, $61,12-13$

Velde, C. (2009). Employers' perceptions of graduate competencies and future in higher vocational education in China. Journal of Vocational Education and Training, 61, 35-51. http://dx.doi.org/10.1080/13636820902819974

Xu, Y. (2009). School-based teacher development through a schooluniversity collaborative project: A case study of a recent initiative in China. Journal of Curriculum Studies, 41, 49-66. http://dx.doi.org/10.1080/00220270802546740 